\title{
CONHECIMENTO, INTELECTO E MEMÓRIA NA UNIVERSIDADE PARISIENSE: UMA LEITURA TOMASIANA
}

Terezinha Oliveira*

\begin{abstract}
RESUMO
O objetivo deste artigo é estudar a relação existente entre o desenvolvimento intelectivo do sujeito e as ações por ele praticadas. As discussões presentes nos projetos educacionais que apontam para a formação de cidadãos reflexivos não consideram a importância do desenvolvimento intelectual da criança e vinculam de forma tênue as práticas dos sujeitos com o seu intelecto. A partir de uma questão da Suma Teológica, de Tomás de Aquino, a questão 79 da $\mathrm{I}^{\mathrm{a}}-\mathrm{II}^{\mathrm{ae}}$, o mestre do século XIII explicita que as atitudes humanas só podem ser compreendidas como expressão do intelecto se as considerarmos da perspectiva do conhecimento e da memória. Ao propormos analisar a relação entre o intelecto e as ações do sujeito, a partir do mestre Tomás, colocamos na ordem do dia o fato de que só se forma cidadãos quando, por meio do intelecto e da memória, o indivíduo compreende e realiza suas ações.
\end{abstract}

PALAVRAS-CHAVE: Filosofia da Educação. Intelecto. Memória. Universidade Medieval

\begin{abstract}
This paper aims at studying the relationship between the subject's intellective development and the actions performed by him. It is observed that, educational projects that aim at forming children to be reflexive citizens, do not consider the relevance of their intellectual development, and just slightly, connect the subject's own practices to his intellect. The

${ }^{*}$ Doutora em História pela Universidade Estadual Paulista /Unesp-Assis e Professora do Departamento de Fundamentos da Educação e do Programa de Pós-graduação em Educação da Universidade Estadual de Maringá. E-mail: teleoliv@gmail.com
\end{abstract}


master of the thirteenth century, Thomas Aquinas - issue $79\left(I^{a}-I^{a e}\right)$ Theological Summa - explains that human attitudes can only be understood as an expression of the intellect if they are considered on the perspective of knowledge and memory. When proposing to examine the relationship between the subject's intellect and actions, based on writings by the master Thomas Aquinas, it is added to present discussions the fact that, citizens are formed, only when the individual understands and carries out his actions by making use of his intellect and memory.

KEYWORDS: Philosophy of Education. Intellect. Memory. Medieval University

Uma das questões que mais nos chama a atenção no âmbito da educação contemporânea, especialmente aquela que se realiza no interior das instituições escolares, é a preocupação com a formação de um cidadão ético, reflexivo, voltado para as problemáticas sociais. Em última instância, um sujeito que saiba agir e se posicionar nos seus espaços de ambiência comum/coletiva. Essa preocupação é encontrada com muita frequência nos projetos políticos pedagógicos oriundos, por seu turno, na maioria das vezes, dos temas transversais propostos nos Parâmetros Curriculares Nacionais (PCNs). ${ }^{1}$ Todavia, muitas vezes, na aplicabilidade dos projetos, no momento do ensino dos conteúdos específicos de cada "disciplina" que constam do componente curricular, nos deparamos com uma grande ausência de reflexão por parte, inclusive, dos professores, formadores do futuro cidadão. A ausência dessa reflexão é o primeiro sinal de que algo vai mal no sistema nacional de ensino porque, se o professor não reflete, também não pode ensinar o seu aluno a prática da reflexão, condição para o aprendizado. Afinal, o que é essa reflexão tão essencial ao ensino, imprescindível à formação de cidadãos? As palavras do professor Pérez Gómez explicitam, com clareza, o que estamos considerando como reflexão.

${ }^{1}$ [...] A ética é um eterno pensar, refletir, construir. E a escola deve educar seus alunos para que possam tomar parte nessa construção, serem livres e autônomos para pensarem e julgarem" (PCN, 1997, v. 8, p.72). 
A reflexão implica a imersão consciente do homem no mundo da sua experiência, um mundo carregado de conotações, valores, intercâmbios simbólicos, correspondências afetivas, interesses sociais e cenários políticos.

O conhecimento acadêmico, teórico, científico ou técnico, só pode ser considerado instrumento dos processos de reflexão se for integrado significativamente, não em parcelas isoladas da memória semântica, mas em esquemas de pensamento mais genéricos ativados pelo indivíduo quando interpreta a realidade concreta em que vive e quando organiza a sua própria existência. A reflexão não é um conhecimento puro, mas sim um conhecimento contaminado pelas contingências que rodeiam e impregnam a própria experiência vital (GÓMEZ, 1992, p. 103)

A reflexão não é algo que se incute na pessoa a partir de uma aula; ela não é conquistada a partir do ambiente comum das experiências cotidianas; também não é fruto somente do conhecimento teórico, mas de tudo isso. Ou seja, o sujeito reflexivo precisa ter uma multiplicidade de saberes que faz com que ele tenha consciência da realidade que o cerca e somente a partir dessa complexa teia que pode agir, tomar atitudes conduzidas pela "vontade consciente", se assim podemos afirmar. Com efeito, a reflexão pressupõe as experiências sociais do presente $e$ o conhecimento construído pela e nas relações sociais ao longo da história.

Nesse sentido, o professor que restringe ou inclina a sua prática docente para apenas um dos lados do processo do conhecimento não consegue incutir em seus alunos a possibilidade da reflexão. Não consegue, portanto, formar o cidadão proposto e desejado pelo PCNs. Mais uma vez, as palavras de Pérez Gómez explicitam esse problema.

[...] quando a prática, pela usura do tempo, se torna repetitiva e rotineira e o conhecimento-na-ação é cada vez mais tácito, inconsciente e mecânico, o profissional corre o risco de reproduzir automaticamente a sua aparente competência prática [...].

Dessa forma, o seu conhecimento prático vai se fossilizando e repetindo, aplicando indiferentemente os mesmos esquemas a situações cada vez menos semelhantes. Fica incapacitado de entabular o diálogo criativo 
com a complexa situação real. Empobrece-se o seu pensamento e a sua intervenção torna-se rígida (GÓMEZ, 1992, p. 106).

O professor que somente pratica a ação docente, que não se preocupa com a formação, que não investiga mais, torna-se inconsciente de sua ação. Como afirma o autor, suas aulas são rotineiras e automatizadas, seus saberes se "fossilizam", porque não há uma continuidade no processo de formação. Eis, em cena, o professor que não reflete e, por conseguinte, não ensina o seu aluno a refletir, seja sobre os conteúdos, seja sobre sua realidade social.

Aliada a essa preocupação em formar cidadãos conscientes e reflexivos, assistimos também a uma grande difusão da ideia de que a criança por si mesma já possui um cabedal de conhecimentos que, a priori, são suficientes para estabelecer os caminhos da sua formação. Evidentemente que esta ideia é fundamental e ninguém poderia afirmar que as crianças não têm incutidas as condições essenciais à aprendizagem. As crianças já possuem condições cognitivas definidas em seu intelecto. Todavia, precisam de pessoas que norteiem o seu caminho, se responsabilizem por sua integridade física e mental e esse papel cabe, indubitavelmente, aos pais e professores, ou seja, aos adultos. Desse modo, é esse sujeito o ser responsável pelo desenvolvimento psicomotor da criança. Nesse sentido, quando nos deparamos com a atividade de ensinar precisamos ter claro qual é o objetivo que pretende ser atendido, que sujeitos queremos formar, qual nosso entendimento sobre educação. Não podemos perder de vista a ideia de que as crianças que educamos no presente serão os atores sociais do futuro, os responsáveis pela gestão da sociedade, das leis. Enfim, se queremos construir uma sociedade mais equitativa, com princípios coletivos, precisamos pensar na educação hoje. Concordamos com Kant quando afiançou, no século XVIII, que a educação da criança no presente precisa ter como meta o sujeito do futuro.

Um princípio da pedagogia, o qual principalmente os homens que propõem planos para a arte de educar deveriam ter ante os olhos, é: não se devem educar as crianças segundo o presente estado da espécie humana, mas segundo um estado melhor, se possível no futuro, isto é, 
segundo a ideia de humanidade e da sua inteira destinação.

Esse princípio é da máxima importância. De modo geral, os pais educam seus filhos para o mundo presente, ainda que seja corrupto. Ao contrário, deveriam dar-lhes uma educação melhor, para que possa acontecer um estado melhor no futuro (KANT, 1996, p. 20-23).

Ensinamos a criança, porque temos como princípio a conservação da sociedade. Pretendemos que os homens vivam em comum e direcionem suas ações, senão para a "comunidade perfeita" como pretenderam Aristóteles e Tomás de Aquino, ao menos para o bem viver. ${ }^{2}$ Quando acreditamos que as crianças já sabem, são senhoras de seus caminhos, no presente, isso implica, certamente, em uma ameaça ao futuro porque estes sujeitos quando forem tomar atitudes, se posicionarem, forem governar, ensinar, não terão a maturidade imprescindível ao bem comum, porque não aprenderam o viver coletivo. Retomemos a ideia, já apontada, segundo a qual a criança tem em si potencialmente a capacidade de aprender, mas não tem o conhecimento histórico e a prática resultante do viver que o adulto professor/pai tem ou deveria ter.

Ao apontarmos para essas duas questões presentes no educar contemporâneo (a ideia da formação do cidadão reflexivo e de que a criança possui o conhecimento a priori), verificamos que se delega ao adulto o papel de orientar e não mais ensinar. Lembramos, ainda, que o que se está vivenciando na educação é próprio de nosso tempo histórico, pois, em qualquer época histórica, os projetos educacionais vigentes espelham

${ }^{2}$ Aristóteles na Ética a Nicômaco, ocupa grande parte do Livro I para analisar e definir o significado de bem, de felicidade para o homem "[...] são nossas atividades conformes à excelência que nos levam à felicidade, e as atividades contrárias nos levam à situação oposta"(ARISTÓTELES, 1985, p. 1100b). Tomás de Aquino, na Suma Teológica, também se dedica a analisar a questão do bem, seguindo, inclusive, o princípio de Aristóteles. "O bem e o ente são idênticos na realidade; eles só diferem quanto à razão. Eis a prova: a razão do bem consiste em que alguma coisa seja atrativa. Por isso mesmo, o Filósofo, no Livro I da Ética, assim define o bem: 'Aquilo para o qual todas as coisas tendem'. Ora, uma coisa atrai na medida em que é perfeita, pois todos os seres tendem para a própria perfeição. Além do mais, todo ser é perfeito na medida em que se encontra em ato. É certo, portanto, que algo é bom na medida em que é ente, pois o ser é a atualidade de todas as coisas, como já se viu [...]" (ST. I a q. 5, a. 1, resposta). 
as questões sociais de seu cotidiano. Precisamente porque hoje temos dificuldades em dirimir conflitos, em tomarmos posições conscientes, em traçar caminhos para o presente, em nos responsabilizarmos pelos atos e atitudes tomadas no dia-a-dia, é que transpomos para a educação de nossos filhos, para nossas aulas, a ideia de que a criança já está pronta, que já tem as respostas.

Esse quadro é um diagnóstico de que nós mesmos não temos explícito o que somos e o que pretendemos conservar do que somos hoje para o futuro, nem sequer temos muito claro os conceitos que foram, em outros tempos históricos, vitais à formação da pessoa, como virtude, ética, moral, sabedoria, dentre uma infinidade de outros que resultam e incidem no agir singular e coletivo dos sujeitos.

Em a Ética a Nicôcamos, obra escrita no século IV a. C., Aristóteles destacou o fato de que as excelências intelectuais e morais são construídas nos homens porque eles as têm em potência e somente mediante a prática, é que elas se tornam a forma de ser dos sujeitos.

Como já vimos, há duas espécies de excelência: a intelectual e a moral. Em grande parte a excelência intelectual deve tanto o seu nascimento quanto o seu crescimento à instrução (por isto ela requer experiência e tempo); quanto à excelência moral, ela é o produto do hábito, razão pela qual seu nome é derivado, com uma ligeira variação, da palavra "habito". É evidente, portanto, que nenhuma das várias formas de excelência moral se constitui em nós por natureza, pois nada que existe por natureza pode ser alterado pelo hábito [...] Portanto, nem por natureza nem contrariamente à natureza a excelência moral é engendrada em nós, mas a natureza nos dá a capacidade de recebê-la, e esta capacidade se aperfeiçoa com o hábito.

[...]

Esta asserção é confirmada pelo que acontece nas cidades, pois os legisladores formam os cidadãos habituando-os a fazerem o bem; esta é a intenção de todos os legisladores; os que não a põem corretamente em prática falham em seu objetivo, e é sob este aspecto que a boa constituição difere da má.

Ademais, toda excelência moral é produzida e destruída pelas mesmas causas e pelos mesmos meios, tal como acontece com toda arte, $[\ldots]$ 
pois é tocando a cítara que se formam tanto os bons quanto os maus citaristas, e uma afirmação análoga se aplica aos construtores e a todos os profissionais; os homens são bons ou maus construtores por construírem bem ou mal. Com efeito, se não fosse assim não haveria necessidade de professores, pois todos os homens teriam nascido bem ou mal dotados para as suas profissões. Logo, acontece o mesmo com as várias formas de excelência moral; na prática de atos em que temos de engajar-nos dentro de nossas relações com outras pessoas, tornamonos justos ou injustos; na prática de atos em situações perigosas, e adquirindo o hábito de sentir receio ou confiança, tornamo-nos corajosos ou covardes. [...] É por isso que devemos desenvolver nossas atividades de uma maneira pré-determinada, pois nossas disposições morais correspondem às diferenças entre nossas atividades. Não será pequena a diferença, então, se formamos os hábitos de uma maneira ou de outra desde nossa infância; ao contrário, ela será muito grande, ou melhor, ela será decisiva (ARISTÓTELES, 1985, p. 35-36).

De acordo com o Filósofo, os homens possuem duas naturezas de excelência: uma moral e outra intelectual. A excelência intelectual existe em todos os homens, em potência, e se desenvolve a partir da instrução. Daí a necessidade, segundo Aristóteles, de professores, porque estes, ao ensinarem as crianças, despertarão nelas suas habilidades intelectuais e, por conseguinte, transformarão suas potências em ato, preparando-os para suas profissões, portanto, para serem adultos.

A excelência moral, por seu turno, também se desenvolve a partir do ensino. Todavia vincula-se ao que se aprende, especialmente fora das instituições educacionais. $\mathrm{O}$ ensino/aprendizagem da excelência moral relaciona-se aos exemplos de comportamentos sociais que aprendemos na família, na Igreja, na comunidade. Ele vincula-se diretamente à prática das virtudes morais, ou seja, se aprende a ser virtuoso, ético, criando o hábito de assim ser. Para o Filósofo, somos aquilo que estamos habituados a ser: se praticamos a justiça desde a infância, criamos o hábito de sermos justos e o contrário também é verdadeiro. Em suma, quando adultos espelhamos as características que aprendemos na infância, daí surge a necessidade de cuidarmos (educarmos) da criança desde a mais tenra infância, pois as duas excelências que expressam o homem principiam a ser formadas a partir disso. 
Os aspectos que, até o momento, apontamos, concernentes à educação - a preocupação com a formação do cidadão reflexivo, a autonomia de conhecimento da criança, a importância das virtudes morais e intelectuais serem ensinadas desde a infância e, acima de tudo, o fato de que cada época histórica tem preocupações específicas no que diz respeito a educação - são similares às discussões que homens do século XIII travaram a respeito desse assunto, pois independente do modelo de homem que cada época histórica exige, em geral, se educa a criança para viver em comunidade, para ter a sabedoria, para ser justa. Com efeito, os escritos de Tomás de Aquino são exemplos desses debates. O mestre Tomás escreve para os homens de seu tempo, inquieta-se com as suas questões e, fundamentalmente, participa do debate teórico travado em seu lócus de ensino, a Universidade.

Elegemos para tratar do ensino e da reflexão uma discussão que Tomás de Aquino faz na Suma Teológica. Trata-se da Questão 79, As Potências Intelectivas, que se encontra na $S T$. $I^{a}-I I^{a e}$. Essa questão consta de 13 artigos e, em todos eles, o mestre discorre sobre o intelecto humano. Cumpre ressaltar que mencionaremos todos os artigos, mas analisaremos apenas alguns deles, aqueles que nos possibilitam uma aproximação mais estreita aos objetivos deste texto. $\mathrm{O}$ artigo $1^{\circ} \mathrm{O}$ intelecto é uma potência da alma? Artigo $2^{\circ}$. O intelecto é uma potência passiva? Artigo $3^{\circ}$ Devese afirmar um intelecto agente? Artigo $4^{\circ} \mathrm{O}$ intelecto agente é parte da alma? Artigo $5^{\circ} \mathrm{O}$ intelecto agente é um só em todos? Artigo $6^{\circ}$. Está a memória na parte intelectiva da alma? Artigo $7^{\circ} \mathrm{A}$ memória intelectiva é uma potência distinta do intelecto? Artigo $8^{\circ}$ A razão é uma potência distinta do intelecto? Artigo $9^{\circ}$ A razão superior e a razão inferior são potências diferentes? Artigo $10^{\circ} \mathrm{A}$ inteligência é uma potência distinta do intelecto? Artigo $11^{\circ} \mathrm{O}$ intelecto especulativo e o intelecto prático são potências diferentes? Artigo $12^{\circ}$. A sindérese é ma potência especial distinta das outras? Artigo $13^{\circ}$. A consciência é uma potência?

É preciso considerar que as questões apresentadas em cada um dos artigos estão vinculadas a um debate maior travado no interior da Universidade de Paris, especialmente em fins de 1260 e início de 1270, que é a discussão construída a partir da entrada dos textos aristotélicos no ensino, especialmente na Faculdade de Artes e na de Teologia. Três 
tendências se apresentavam em cena: os seguidores de Aristóteles, os agostinianos (seguidores dos princípios de santo Agostinho) e aqueles que se apresentavam como influenciados pelas duas tendências (Aristóteles e Agostinho). A discussão do mestre Tomás sobre o intelecto é partícipe desse debate. $\mathrm{O}$ mestre Aquinate se posiciona contra os agostinianos, que acreditavam que o intelecto humano existia e agia somente a partir da luz divina, ${ }^{3}$ seja contra aqueles que consideravam que os homens possuíam um único intelecto, e esse, por sua vez, independia da vontade de Deus. Seu principal opositor, nessa tendência, foi Averróis. Santo Tomás escreveu um texto intitulado "Unidade do Intelecto" contra os Averroístas para combatêla. No primeiro parágrafo desse texto o autor já esclarece o seu propósito.

Como todos os homens, por natureza, desejam saber a verdade, também neles é natural o desejo de fugir dos erros e de os refutar quando têm essa faculdade. Ora, entre todos os erros, o mais inconveniente parecer ser aquele em que se erra sobre o intelecto que naturalmente nos habilita a conhecer a verdade evitando os erros. Há já algum tempo que se implantou entre muita gente um erro acerca do intelecto. Originado nos escritos de Averróis, consiste em defender que o intelecto a que Aristóteles chama 'possível', e que Averróis designa impropriamente pelo nome 'material', é uma substância separada do corpo segundo o seu ser, que de modo nenhum se une ao corpo como forma. Mais ainda: Averróis defende que o intelecto possível é único para todos os homens (AQUINO, A unidade do intelecto ..., cap. I, § 1).

Do ponto de vista do mestre dominicano, o erro de Averróis estava em considerar que o intelecto humano era único para todos os homens; se fosse assim todos os homens pensariam a mesma coisa para todas as situações, não existiria divergência de opiniões. E mais, segundo Averróis, o intelecto seria uma matéria singular e própria que existiria independentemente. Santo Tomás diverge dessa ideia e a considera um erro, porque, de acordo com a sua leitura de Aristóteles, o intelecto é uma

${ }^{3}$ Um dos maiores representantes desta tendência é São Boaventura de Bagnoregio. A sua obra, o Itinerário da mente, é uma defesa da ideia de que os homens pensam e agem mediante vontade divina. 
potência que pode se transformar em ato, logo não pode ser separado do corpo e não é um elemento singular porque não tem existência independente. Discorda também em virtude do conhecimento dos escritos sagrados porque, ainda que cada homem possua seu intelecto e vontade própria como parte de si, o intelecto foi criado por Deus.

Essa perspectiva de análise na qual se considera as duas vertentes do conhecimento é constante em Tomás de Aquino e, aliás, aparece em todas as suas formulações, ou seja, elas sempre estão norteadas pelos Escritos Sagrados e por Aristóteles. Nesse sentido, no mestre, todos os fatos, os elementos da natureza, têm sempre, pelo menos, duas possibilidades de conhecimento, a espiritual e a material. Elas aparecem também quando Tomás reflete sobre o conhecimento humano, ainda no debate com Averróis.

Há, porém, uma diferença entre o sentido e o intelecto, é que o sentido não tem capacidade para conhecer tudo, mas a vista conhece apenas as cores, o ouvido, os sons, e assim sucessivamente. Já o intelecto é absolutamente capaz de conhecer tudo. Julgando que aquilo que conhece deve ter a natureza do conhecido, os antigos filósofos diziam que para que a alma conheça tudo é preciso que seja composta dos princípios de todas as coisas. Mas dado que Aristóteles já tinha provado que o intelecto, à semelhança do sentido, não é em ato, mas é apenas em potência, aquilo que conhece, conclui ao contrário: $<<$ é necessário que o intelecto, visto que conhece tudo, seja sem mistura $>>$, isto é, não composto de todas as coisas, contrariamente ao que Empédocles sustentava (AQUINO, A unidade do intelecto (...), cap. I, § 20).

De acordo com mestre Aquinate, o intelecto não pode ser único, entre outras razões, porque há no homem duas naturezas de conhecimento: a proveniente dos sentidos e a oriunda do intelecto agente. $\mathrm{O}$ conhecimento intuitivo é aquele derivado dos sentidos: a pessoa percebe tudo o que a cerca por meio da visão, do tato, do paladar, do ouvido, portanto, é o conhecimento pertencente ao homem como animal. Todavia, o homem também possui o intelecto e é a partir dele que o indivíduo constrói o pensamento reflexivo, desenvolve potencialmente o livre-arbítrio. É, pois, a partir do intelecto que o homem toma decisões, reflete, apreende as questões abstratas. Sob 
esse aspecto é esta natureza de conhecimento que o diferencia dos demais animais por possuir a razão reflexiva "[...] ora, a operação própria do homem, enquanto é homem, consiste em pensar, pois é nisto que difere dos animais [...]. O princípio pelo qual pensamos é o intelecto, tal como Aristóteles diz" (AQUINO, A unidade do intelecto (...), cap. III, § 77). Para o mestre dominicano, seguindo os passos de Aristóteles, o homem é homem porque pensa, e o pensar só é possível por meio do intelecto que, por sua vez, não é um corpo próprio, mas parte integrante da alma. Por conseguinte, é também a parte do homem que se assemelha a Deus.

Ao retomarmos as formulações tomasianas na obra "A unidade do intelecto contra os averroístas" pretendemos explicitar que sua discussão sobre as Potências Intelectivas, presente na Questão 79, faz parte de um debate maior. As proposições de santo Tomás têm um sentido histórico e são permeadas pelos embates da segunda metade do século XIII. Não se trata, portanto, de algo isolado. É porque os intelectuais de seu tempo buscavam entender a natureza do ser reflexivo que ele participa do debate e explicita suas ideias. Assim, o mestre Tomás defrontava-se, da mesma forma como ocorre conosco atualmente, com questões que se colocavam para a sociedade em sua época. Exatamente pelo fato de Aquino conceber o ser humano a partir do intelecto e da potência reflexiva é que retomamos suas reflexões, pois, em nosso entender, a época em que vivemos exige igualmente um ser reflexivo, uma pessoa capaz de agir a partir do seu livrearbítrio. Este é, com efeito, o cidadão que necessitamos.

Para tratarmos desse ser reflexivo em santo Tomás, elegemos, dos 13 (treze) artigos mencionados anteriormente, o artigo $1^{\circ}, O$ intelecto $e$ uma potência da alma?; o artigo $3^{\circ}$, Deve-se afirmar um intelecto agente?; o artigo $6^{\circ}$, Está a memória na parte intelectiva da alma?; e o artigo $13^{\circ}$, A consciência é uma potência? Nesses quatro artigos destacados, a tônica dominante é a discussão acerca da definição do que seja o intelecto humano e qual a sua importância no agir da pessoa.

RESPONDO. É necessário afirmar, em vista de tudo o que precedeu, que o intelecto é uma potência da alma, e não sua existência. Com efeito, o único princípio imediato da operação é a essência mesma do que opera, quando a própria operação é seu ser. Pois, assim como 
a potência está para a operação como seu ato, assim está a essência para o ser. Ora, somente em Deus conhecer é a mesma coisa que o seu ser. Portanto, só em Deus o intelecto é a essência; nas outras criaturas dotadas de intelecto, ele é uma potência do que conhece.

[...]

Quanto ao $4^{\circ}$, deve-se dizer que a mesma imaterialidade da substância inteligente criada não é seu intelecto, mas é por ser imaterial que ela tem poder de conhecer. Não é necessário, portanto, que o intelecto seja a substância da alma, mas que seja a sua força e potência $\left(S T\right.$, I ${ }^{\mathrm{a}} \mathrm{II}^{\mathrm{ae}} \mathrm{Q}$. 79 , art. 1, resposta, ad. 4).

Ao prosseguir a discussão sobre a natureza do intelecto, mestre Tomás destaca que o intelecto humano não é único e perfeito, porque ele se constitui em uma potência, ou seja, ele pode vir a ser, mas não é. Somente em Deus o intelecto é perfeito, porque ele, segundo o autor, é em ato e o seu ser conhece todas as coisas, diferentemente dos seres humanos que precisam conhecer para depois saber. Nos homens, o intelecto é condição do seu ser racional, porque todos, potencialmente, podem saber em ato, mas só sabem após conhecer, não existindo, a priori, a sabedoria em ato.

No artigo $3^{\circ}$, santo Tomás ressalta o fato de que o inteligível não existe no conhecimento sensível, nas coisas materiais. Não podemos tocar ou sentir o intelecto. Logo, ele se torna possível e conhecível, em ato, quando pensamos, ou seja, é por meio da abstração que se ele torna real, compreensivel.

Ora, o inteligível em ato não é algo existente na natureza, ao menos na natureza das coisas sensíveis que não subsistem fora da matéria. Por isso, para conhecer não bastaria a imaterialidade do intelecto possível, se não houvesse intelecto agente, capaz de tornar os inteligíveis em ato por meio da abstração (ST, I ${ }^{\mathrm{a}} \mathrm{II}^{\mathrm{ae}} \mathrm{Q} .79$, a. 3, resposta, ad. $\left.3 \mathrm{~m}\right)$.

Ao afirmar que o inteligível se torna ato por meio da capacidade abstrativa do homem e que "a operação própria do homem, enquanto é homem, consiste em pensar", o mestre dominicano inaugura uma leitura singular sobre o que seja o próprio homem. Somos sujeitos, porque pensamos, compreendemos e agimos de acordo com nossas capacidades 
intelectivas. Em última instância, é a nossa capacidade de abstrair que nos torna seres reflexivos. Esse conhecimento que Tomás de Aquino valoriza no homem é o nosso intelecto cognitivo que é, igualmente, o que nos aproxima do Ser supremo. Evidentemente, o mestre relaciona esse conhecimento a Deus, mas também concede ao homem um status de ser superior, quase perfeito. Indubitavelmente produz uma revolução no entendimento que se tinha das ações humanas, pois o homem que reflete, que possui livre-arbítrio para definir seus atos, é também $o$ responsável por suas ações. Assim, Deus daria ao ser humano o intelecto cognitivo, mas é ele, homem, o responsável pelo seu uso.

Por considerar que os homens são responsáveis por suas ações, no artigo $13^{\circ}$ da Questão 79, A consciência é uma potência? Santo Tomás destaca o fato de que, se o intelecto existe no homem enquanto potência, a consciência existe enquanto ato. Por conseguinte, como ser consciente o homem sempre sabe o que faz. Segundo o mestre é nossa consciência que esclarece se nossa atitude é correta ou equivocada. Nossos atos decorrem, portanto, de nossa consciência que, por seu turno, realiza nossas vontades segundo nosso conhecimento. Nesse sentido, consciência é ato e não potência, e quanto mais o homem conhece, mais consciência e discernimento ele têm do seu agir.

[...] segundo a etimologia, é evidente que a consciência é um ato. A mesma conclusão se impõe a partir do que se atribui à consciência. Diz-se que a consciência atesta, obriga ou incita, e ainda acusa ou reprova ou repreende. Ora, tudo isso resulta da aplicação de algum conhecimento ou ciência que temos do que fazemos. O que se realiza de três maneiras: 1. Quando reconhecemos ou não tal ação. Como diz o Eclesiastes: "Tua consciência sabe que tu maldisseste muitas vezes os outros". E nesse sentido diz-se que a consciência atesta. 2. Quando, por nossa consciência, julgamos que é preciso fazer ou não fazer tal ação. Diz-se então que a consciência incita ou obriga. 3. Quando julgamos, pela consciência, que o que foi feito, foi bem feito ou não. E então se diz que a consciência escusa, acusa ou reprova. É claro que tudo isso resulta da aplicação atual de nosso conhecimento à nossa ação. Por isso falar com propriedade, a consciência designa um ato (ST, I ${ }^{\text {a IIe }}{ }^{\text {ae }}$ Q. 79, a. 13, resposta). 
Desse modo, o intelecto cognitivo deixa de ser potência por meio do ato humano e a consciência é o ato em si. Todavia, tanto o intelecto quanto a consciência encontram-se estreitamente ligados e dependem do conhecimento que o homem tem de si e das relações que o medeiam. Seguindo a linha de raciocínio tomasiano não é possível um ser atuante, reflexivo, ou como exigimos hoje, um ser cidadão, se não houver o conhecimento e responsabilidade nos atos do sujeito. É exatamente isso que santo Tomás chama de consciência. Quando afirmarmos que a educação atual precisa formar pessoas conscientes, cabe indagar se estamos propiciando a eles o conhecimento e a responsabilidade por seus atos para que disso decorra a consciência cidadã tão almejada? O mestre dominicano tinha isso muito claro. O habitante citadino do século XIII que convivia com as mais variadas pessoas e diversas tendências do conhecimento, na cidade e na Universidade de Paris, locus de onde partia o discurso de Tomás de Aquino, precisava ter conhecimento e consciência dos acontecimentos e das diversidades de seu tempo.

A nosso ver, a preocupação com o conhecimento é uma das razões pelas quais santo Tomás também analisa nessa Questão a memória. Essa discussão encontra-se no artigo $6^{\circ}$ Está a memória na parte intelectiva da alma? e no artigo 7. A memória intelectiva é uma potência distinta do intelecto?

A preocupação com a memória também está presente em nosso ofício como professor e como pesquisador. Não é possível compreender a história, os processos pedagógicos, sem a memória. No nosso caso, tal como certamente o fora para santo Tomás, o conhecimento dos conhecimentos passados, produzidos pelos homens ao longo da história, ao que os homens medievais chamavam de autoridade e nós de clássicos, foi e é uma das condições essenciais para a produção de novos saberes.

Evidentemente, para o mestre dominicano, em virtude da especificidade de seu tempo, essa memória se conservava, especialmente, pela escrita, pela pintura, pelos monumentos e, em alguns casos, pelos jograis que se conservaram, também, por meio da narrativa escrita. Para nós, a memória é conservada pelo escrito, pelo oral, pela imagem fílmica, fotográfica, dentre outras. Nosso tempo tem condições diversas de preservar a memória, diferentemente do século XIII. Entretanto, Tomás 
de Aquino, diferentemente de nós, precisava explicitar aos homens de seu tempo não só a importância da memória, mas a razão primeira da sua existência. Dito de outro modo, que a memória fazia parte do ser sujeito, que era parte do seu intelecto e também da sua materialidade posto que sempre que lembramos, lembramos de algo que já passou ou está em via de se tornar passado, porque já se tornou ato, se materializou, por isso temos sua imagem.

O mestre dominicano precisa evidenciar que a memória faz parte do intelecto e da matéria. No intelecto, a memória existe enquanto imagem, pois é capacidade cognitiva do homem que faz com que ele se lembre e, ao mesmo tempo, reproduza o acontecimento passado na sua mente.

Ressaltemos uma questão importante acerca da ideia de imagem. Hoje, quando falamos de imagem, nos vem à mente a imagem material de algo, de uma pintura, de uma construção, de um episódio histórico, como a Revolução Francesa, por exemplo. Mas, para o homem medieval, a imagem estava também vinculada à imaginação que se criava das coisas. Aliás, o homem medieval foi, sempre, carregado de imagens mentais, especialmente as concernentes à fé. Por princípio, ser cristão era crer em um Deus criador de todas as coisas materiais, mas que Ele mesmo era imaterial, invisível. Assim, mentalmente, construíam uma imagem de Deus por meio da pura abstração.

Outro dado significativo, ensinado por Tomás de Aquino, no que diz respeito à memória e, sob este aspecto nossa observação não se limita à Idade Média, é que a memória, enquanto parte do intelecto, só existe no homem. Por conseguinte, somente nós somos capazes de criar a memória intelectiva, portanto, preservar, por meio dela, o passado. Sob este aspecto estamos destacando aquilo que o mestre designa como parte material ou sensível da memória. Nós, como os demais animais, lembramos de nossas necessidades materiais cotidianas, sentimos fome, lembramos como nos alimentarmos, sentimos sede, sabemos que se ingerirmos líquido a saciaremos. Essa memória é material. Todavia, santo Tomás destaca outro aspecto da memória que precisa ser mencionado. A memória enquanto parte do intelecto participa de uma materialidade corpórea (caixa craniana/ corpo). Assim, ainda que o intelecto seja abstrato e exista, em potência, em todos os seres humanos, só existe em sua totalidade no homem posto 
que ele é corpo e intelecto/alma. Assim, a memória enquanto elemento intelectual e material, somente existe no sujeito histórico homem. Nos demais animais a memória existe apenas sob o aspecto sensitivo, como já mencionamos anteriormente.

Prosseguindo acerca da discussão do Aquinate sobre a memória, destacamos, como um dos aspectos mais importantes, a construção da história. Santo Tomás chama a atenção para o fato de que somente o homem, pela sua memória intelectual, é capaz de estabelecer a noção de temporalidade, ou seja, passado, presente, futuro. É porque o homem possui memória que pode construir, conservar e situar-se no tempo. Do ponto de vista do mestre dominicano, a memória faz com que lembremos das ações humanas, que são sempre acidentais. ${ }^{4} \mathrm{O}$ homem, pela memória conserva o passado, produz o conhecimento e as suas ações do presente construirão a história do futuro.

O intelecto conhece o homem enquanto tal; mas ao homem enquanto tal é acidental estar no presente, no passado ou no futuro. Todavia, no que se refere ao ato de conhecer, a condição de passado pode encontrar-se por si tanto no intelecto como nos sentidos. Pois o conhecer de nossa alma é um ato particular, que se realiza em tal ou qual momento, e em conformidade com isso se diz que o homem conhece agora, ontem ou amanhã. $E$ isso não vai contra a natureza do intelecto, porque esse ato de conhecer, embora particular, é contudo um ato imaterial, como foi dito acima a respeito do intelecto. Em conseqüência, como o intelecto se conhece a si mesmo, embora seja um intelecto singular, da mesma forma conhece sua intelecção, que é um ato singular, ou no passado, ou no presente ou no futuro. - Assim fica salva a razão da memória, com relação aos atos passados, no intelecto, enquanto conhece que conheceu anteriormente, mas não enquanto conhece o passado, em determinado tempo, aqui e agora $\left(S T, \mathrm{I}^{\mathrm{a}} \mathrm{II}^{\text {ae }}\right.$. Q. 79 , art. 6, resposta, ad. $1,2$ e $3 \mathrm{~m})$.

\footnotetext{
${ }^{4}$ Ressaltamos que o conceito de acidente para os medievos, particularmente para santo Tomás, está relacionado às ações que os homens praticam no seu cotidiano, ou seja, tudo que é feito pelo homem é acidental. Portanto, acidente não tem o sentido de tragédia que em geral lhe atribuímos na atualidade.
} 
Desse modo é o homem, por meio de suas relações sociais, pelo fato de possuir potencialmente um intelecto cognitivo, pelo conhecimento e consciência de seus atos, por poder construir, pela memória, uma noção temporal do hoje e do ontem, constrói e, concomitantemente, cria as noções de tempo e de história. Faz mais do que isso: pela sua capacidade intelectiva toma decisões nesse tempo histórico criado e essas decisões "acidentais" convergem para o fim da existência humana em um dado tempo. Fim não no sentido de fim dos tempos (no sentido apocalíptico), mas como a forma de ser dos sujeitos em uma dada ambiência. No caso de santo Tomás, esse espaço temporal era o citadino, das universidades, do comércio no século XIII. No nosso caso, a da democracia para todos, escolas para todos. Em suma, época por excelência da construção de seres reflexivos e cidadãos, ao menos no nível do discurso e dos projetos pedagógicos.

A questão que fica para nós, enquanto historiadores da educação deste tempo presente, da discussão apresentada por santo Tomás nesta Questão 79 e analisada neste texto é a seguinte: nossos alunos, futuros adultos, responsáveis pela sociedade do amanhã, têm clareza do que seja essa potência intelectiva e que é dela que emana a responsabilidade por todos os atos praticados aqui e no futuro? Esperemos que ao menos nós, professores, saibamos despertar o intelecto que existe em potência em todos os nossos alunos para que tenham clareza de que todos os atos praticados são de sua inteira responsabilidade e que dessas ações dependem o tempo futuro e a preservação da história/memória. Por conseguinte, do próprio homem. Por fim, tenhamos consciente o que o mestre dominicano nos ensina: ser reflexivo é aquele que tem o conhecimento e dele retira seus atos e que o seu agir deve ser prenhe de consciência.

\section{Referências}

ARISTÓTELES. Ética a Nicômacos. Brasília: UnB, 1985.

BRASIL. Secretaria de Educação Fundamental. Parâmetros Curriculares Nacionais: Apresentação dos Temas Transversais e Ética. Brasília, 1997. KANT, E. Sobre Pedagogia. Piracicaba: Unimep, 1996. GÓMEZ, A. P. O pensamento prático do professor. In: NÓVOA, A. 
(Coord.). Os professores e a sua formação. Lisboa: Dom Quixote, 1992, p. 93-114.

AQUINO. Tomás de. Suma Teológica. São Paulo: Loyola, 2002, v. II - q. 44 a 119.

. A unidade do intelecto contra os averroístas. Lisboa: Edições 70, 1999.

Data de registro: 01/06/09 Data de aceite: 28/08/09 